\title{
Editorial
}

\section{The Institutional Economics of Water}

\author{
Rathinasamy Maria Saleth \\ Madras School of Economics \\ Chennai, India \\ r.saleth@gmail.com
}

Published 11 July 2018

\section{Introduction}

Regardless of their diverse disciplinary backgrounds and ideological orientations, water experts and policy-makers around the globe evince a remarkable level of consensus on the diagnosis that water crisis is a direct outcome of "governance crisis". The focus on governance underlines the central role of water institutions. Water institutions are structures defined interactively by both formal elements (laws, policies, and organizations) and by informal elements (customs, norms, and conventions). It is these structures that create the incentive environment and operational framework for managing water demand across uses and developing water supply across sources. Appropriate water institutions are, therefore, indispensable to promote sustainable use, allocation, and management of water at various regional and sectoral scales. To perform such a role, water institutions, which are structured and embedded within the larger physical, social, economic, and political setting of a country or a region, have to adaptively evolve and constantly improve their performance to fit with the changing conditions. Although a variety of forces - both economic and non-economic - are at work within this process of institutional change and performance, they operate largely through an economic calculus. The task of the institutional economics of water is, therefore, to unravel these forces, their underlying rationale, and their implications for the process of 
institutional change and performance within the water sector, while utilizing different analytical, methodological, and empirical approaches.

A quick review of the existing literature on the institutional economics of water reveals the way in which the institutional issues in water sector are approached and evaluated. The change and performance of water institutions can be evaluated with different analytical perspectives and functional levels. The focus can be on the feature and performance of either individual institutional elements (e.g., norms/ customs, property rights, pricing, and water markets) or structural components (e.g., water laws, water policies, and water organizations). The evaluation can also focus either on the operation of water institutions at regional and sectoral scales or on the structure, reform, and performance of water institutions, taken as a whole, from national or macro perspectives. From a methodological perspective, depending on the focus of evaluation, the analysis can be based on descriptive, conceptual, analytical, or empirical approaches. This special issue on the institutional economics of water aims to showcase some illustrative examples of the kind of studies that are ongoing in the area of water institutions in the recent years.

\section{Overview of the Papers}

This special issue includes nine papers with varying focus, coverage, and methodologies. The focus of the papers ranges from general and cross-country context to location-specific and country-specific setting. The methodology ranges from econometric and historical analysis to analytical and case study evaluation. The institutional elements being evaluated by some papers are very direct and explicit while others are indirect and subtle. But, taken together, these papers provide a clear exposition of the way institutional aspects play a strong role in the operation and performance of water sector in the changing environment under diverse physical, socio-economic, and political settings. The importance and implications of these papers for current policy and direction for future research is specified after a quick overview of each of the papers included in this special issue.

\subsection{Fiscal efforts as a proxy for water governance}

Conceptual, methodical, and data limitations prevent a direct and explicit evaluation of water institutions or water governance per se. Unlike their structural and functional aspects involving complex multi-disciplinary dimensions, their outcomes are relatively easy and straightforward to capture and evaluate, especially from an economic perspective. Bromley and Anderson illustrate the feasibility and validity of this approach econometrically using cross-country data in their paper: “Does Water Governance Matter?”. Developing a set of diagnostic models that use 
economic, social, and water-related data pertaining to 82 of the world's poorest countries during 1991-2015, they demonstrate first that improved water and sanitation services contribute to per capita GDP both directly as well as indirectly via improved public health outcomes. Having established the relation between water-related services and economic performance, they, then, derive a proxy variable to capture subtle but fundamental linkage between the level of water-related service and the quality of water governance. This proxy variable or "index of instrumental governance" is related to the extent to which governments make difficult financial commitments to improve the income and livelihood prospects of their citizens.

It is clear from the paper that water governance, though cannot be directly observed, can, however, be evaluated indirectly through their economic, social, and political impacts. It is in this respect, Bromley and Anderson use fiscal efforts or investment commitments of the government as a proxy or instrumental variable to capture the performance of water governance and its underlying institutions. Thus, by considering the level and quality of water-related services as an index of governance and relating this, in turn, with the economic, health, and educational performances across sample countries, the authors have established that water governance does matter for economic and social performance from an overall macro perspective. It is recognized, however, that the nature of the relationship between fiscal effort and governance performance may not be the same in the entire range of the relationship. With an advanced governance system, even a small fiscal effort could lead to disproportionate improvement in performance and vice versa. In this sense, fiscal effort becomes a function of the quality of governance itself.

\subsection{Transaction costs of physical and virtual water transfer}

Often, physical water transfer and virtual water trade are debated as alternative options for addressing inter and intra-regional water scarcity without considering their differential institutional and technical requirements. Dinesh Kumar, in his paper: "Physical Transfer of Water vs. Virtual Water Trade: Economic and Policy Considerations", addresses this overlooked issue within the Indian context, using a transaction cost perspective. The analytical framework of the paper explains well the differential institutional, economic, and technological implications and requirements of the two options. Virtual water trade cannot occur without proper legal, policy, and organizational framework for trade within and across regions. Similarly, physical water transfer requires technical and physical structures for water movements. When one wants to compare the two, then, it is necessary to account for the tremendous costs involved in creating the enabling institutional and 
technical conditions for the two options and that has to be contrasted with the expected benefits from them.

The institutional, economic, and technological aspects set the transaction cost framework being used in this paper. The framework covers not only the economic and technical aspects but also the institutional dimensions of the two alternatives. Categorizing regions within India as land-rich and water-scarce regions and landscarce and water-rich regions and using secondary data and anecdotal evidences on various direct and indirect costs and benefits, the paper concludes that the net benefits of physical water transfer far outweigh virtual water transfer. Although executing physical water transfer projects involves serious political transaction costs, they cannot be ruled out or substituted by politically expedient policies involving small water projects or geographically diffused water conservation works. Dinesh Kumar argues that undertaking large water projects and implementing consonant institutional reforms will be a key long-term water strategy for solving the inter-regional water scarcity problems in India.

\subsection{Institutional requirements of market-based incentives}

While market-based incentives can complement regulatory approaches in promoting water conservation in watersheds, such incentives cannot occur in an institutional vacuum. This is the central theme of the paper: "Lessons from Applying Market-based Incentives in Watershed Management” by Muchapondwa, Stage, Mungatana, and Kumar. Using a meta-analysis of information collected from 26 watershed initiatives spread across Africa, Asia, Europe and the Americas, Muchapondwa et al. evaluate the role of institutional mechanisms, especially those required for generating market-based incentives for water conservation. The crosscountry cases are reviewed in terms of their physical and technical conditions, overall institutional and policy environment, nature of market-based incentives used, and the actual outcomes from watershed interventions. The aim is to identify the market-based incentives and their supportive institutional conditions, which can promote direct community and private sector participation in wide variety of watershed contexts.

From an institutional economics perspective, the paper makes an important observation that the victim pay principle is not the first best because of the prevailing institutional distortions related to the existence and effectiveness of property rights. But, such distortions are themselves a direct outcome of the transaction costs of creating/enforcing property rights. As long as the payments to polluters are lower than these transaction costs, it would be optimal for victims to pay the polluters. But, if the payments to polluters exceed the institutional transaction 
costs, then, optimality would necessitate the creation of these property rights and their enforcement mechanisms. From a policy perspective, this paper argues for an increased reliance on market-based incentives, not as a substitute but as a complement to the generally used regulatory approaches. But, appropriate legal and institutional arrangements are needed for the market-based incentives to be effective in promoting local community participation. Similarly, packaging watershed programs with forward and backward linkages is critical to incentivize private sector.

\subsection{Evolution of institutional structures for water supply sector}

Water institutional structures at the national and sectoral levels evolve through a long historical process of mediation and negotiation in which different configurations of social, economic, political, institutional and technological factors have played distinct roles during different facets of the process. This is the main hypothesis that is being developed and tested by Zetland and Colenbrander in their paper: "Water Civilization: The Evolution of the Dutch Drinking Water Sector". Having presented an analytical narrative of the historical evolution of the drinking water sector in the Netherlands during a period of a century and a half between 1850 and 1990, Zetland and Colenbrander argue that the current state of universal coverage of safe and affordable drinking water being observed in the Netherlands is an outcome of an evolutionary process marked by four distinct eras. Over these four eras, the Dutch drinking water sector made a full circle, i.e., from a private good approach to resolve the common pool dilemma (1850-1880) to a club good solution (1880-1910), then, to a public good approach with subsidy to the poor (1910-1950), and, finally, returning back to a private good approach with emphasis on cost efficiency and resource sustainability (1950-1990).

Notably, the paper also describes how these evolving approaches led to corresponding changes or reforms in the institutional structures governing the Dutch drinking water sector during the four eras. The institutional changes and reforms cover not only various water and water-related laws and regulations but also the policies, especially those pertaining to water pricing and pollution taxes. They also cover the creation or reorientation of different organizations functioning within the Dutch drinking water sector. The paper also evaluates the impacts in terms of the causal link between outbreak of water borne diseases and water pollution as well as the relationships such as that between water consumption and reduction in infant mortality. The narrative of how the new Health Care Law changed the economics of drinking water supply provides an illustration for the inter-sectoral economic and institutional linkages. Similar is also the case with the effects of changing democratic 
processes, especially the role of "podering" or negotiation among interest groups on the nature and pattern of government spending in the drinking water sector.

\subsection{Institutional limitations of river basin organizations}

What effects institutional incoherence and internal institutional conflicts will have on the overall performance of river basin organizations are illustrated well by the interesting French case study: "The Rise and Fall of the French Agences de l'Eau: From German-Type Subsidiarität to State Control” by Barraqué, Laigneau, and Johnsson. After a detailed historical analysis of the French Water Agencies in the particular context of their role in controlling water pollution within a river basin, the authors compare the French Water Agencies with their German and Dutch counterparts both from an organizational angle and also in terms of functional effectiveness and operational performance. Although the French Water Agencies were inspired by the Dutch and German water boards, they differ due to their weak planning power and lack of ownership or police powers. Also, they have a larger jurisdiction with only an indirect participation of users through their elected representatives. Although the Agencies have developed over the years the principle of reasonable use and the separation of use rights from ownership rights, the 1992 law reversed water back to the status of a public trust or common pool resource.

Moreover, since the charges levied by the Agencies are considered as taxes, instead of user fees, their budget is subject to parliament control, limiting their functional autonomy further. As structures for river basin management, therefore, the French Water Agencies are organizationally fragile and quasi-constitutional in nature. As a result, they are not able to adopt and implement the market-based instruments as mandated by the Water Framework Directives of the European Union. Overall, the institutional and organizational features of the Agencies are at odds not only with the general constitutional principles of the country but also with the internal and external requirements of the French water sector. Unless the French Constitution is modified to provide the room for the Agencies to create specific institutions to manage common pool resources, the level of their institutional complexity and operational incoherence could limit their functional performance as river basin institutions. The authors, therefore, argue for the urgent need to undertake a thorough reevaluation of the concepts and ideas and a radical reform of laws and policies currently underlying the French river basin institutions.

\subsection{Perverse effects of groundwater institutions}

An important but less addressed dimension of institutional research in general and water institutional research in particular pertains to the potential externalities or 
perverse side-effects caused by faulty institutional and policy design or implementation contexts. Sears, Lim, and Lawell address this specific issue in their paper: "The Economics of Agricultural Groundwater Management Institutions: The Case of California”. Using the case of groundwater management institutions and policies that are being implemented and planned to promote groundwater conservation in California, Sears et al. not only illustrate how the perverse effects are an outcome of faulty design and implementation but also show how these effects can be countered through both institutional and non-institutional approaches. Policies involving grants for the adoption of evapotranspiration-based irrigation scheduling, micro-irrigation or drip systems, pressurized irrigation systems, and rebates for shifting from high-pressure to low-pressure drip systems do promote groundwater use efficiency. Similarly, input subsidies can also enhance water use efficiency by promoting private investment on irrigation technologies.

This paper argues that improved use efficiency may not necessarily lead to groundwater conservation due to certain perverse effects. Although the policies that subsidize advanced irrigation technologies promote water use efficiency and conservation at farm level, they actually lead to the opposite effect of groundwater overuse at regional or sectoral scale. This is due to the rapid expansion of production in marginal land and fast shift from dryland to irrigated agriculture. Besides, the subsidy programs also have a self-selection bias because participants, who would have invested in the irrigation technologies without the subsidy, get public funds that could have been used more productively elsewhere. For eliminating the perverse effects and creating powerful economic incentives for groundwater conservation in California, Sears et al. advocate a solution that involves not only the institutional framework centered on property rights but also the management framework based on dynamic, conjunctive, and spatial management of groundwater resources.

\subsection{Institutional sustainability of local water organizations}

The intricate institutional and operational linkages that local level water organizations have with the regional level legal and policy systems and local level social, economic, and political environment is the focus of the paper: "Democratic Local Institutions for Sustainable Management and Use of Minor Irrigation Systems: Experience of Pani Panchayats in Odisha, India”. In this paper, Behera and Mishra evaluate the institutional environment, structure and operational performance, and emerging challenges of local level water organizations, i.e., Pani Panchayats (water councils), in the Indian state of Odisha. The institutional environment of Pani Panchayats is interpreted using Williamson's framework with four functionally 
linked but analytically distinct institutional levels, i.e., embedded setting (set by informal but durable norms, customs and traditions), institutional environment (set by purposive but changeable formal rules from constitutions, laws, and property rights), governance structure (set by formal and informal contractual relations), and actual resource allocation and use (set by economic signals and market rules).

Field level data collected from sample irrigation projects show that Pani Panchayats are very effective in efficiently managing their irrigation projects, especially with respect to key aspects such as water service pricing, water allocation, and system maintenance. The consequent improvement in water use efficiency and the expansion of irrigated area have also promoted agricultural intensification and social inclusiveness in the area under the irrigation projects managed by Pani Panchayats. The paper also identifies some major problems that are actually originating from the very socio-economic, political and institutional milieu within which the Pani Panchyats are operating. These problem include issues such as 'elite capture' (the decision-making dominance of powerful few), non-separation of land and water rights, exclusion of landless from water rights, energy constraints, and the absence of supporting institutions such as farm input and marketing networks. Behera and Mishra conclude that the functional performance and institutional sustainability of Pani Panchayats cannot be ensured unless these serious problems are addressed through further institutional and policy reforms.

\subsection{Effects of users' characteristics on local water governance}

Contextual factors such as social characteristics of users and physical setting of the resource play a powerful role in human behavior, institutional design, and resource performance. In their paper: "The Role of Homogeneity and Heterogeneity among Resource Users on Water Governance: Lessons Learnt from an Economic Field Experiment on Irrigation in Uzbekistan”, Roßner and Zikos address this important issue within an interesting empirical setting. They examine the behavior of water users under different institutional and physical settings using data generated from an economically framed field experiment conducted within a game theoretic framework involving a set of 20 farmers in an Uzbek community. The experiment involves several rounds of irrigation games, face-to-face communication, random assignment of upstream-downstream location, asymmetric farm size and power, and differing systems of water allocation (randomized, rotational, and property rights-based). By comparing the relative effects of externally imposed and internally designed rules of water allocation on homogeneous and heterogeneous groups of irrigation users, the paper illustrates the roles played by institutional rules, physical location of farms, and economic characteristics of users in promoting cooperation within hybrid and diverse governance structures. 
Based on the experimental results, the paper demonstrates that homogenous groups with similar endowments and features are more inclined to comply with self-designed rules than the heterogeneous groups due to the effects of similar economic incentives. The homogenous groups also evince better performance with respect to aspects such as resource maintenance and water harvesting under the condition of self-governance. Notably, internally designed and implemented rules lead to more equal and decreased illegal withdrawals irrespective of the homogeneity or heterogeneity of the groups. The paper argues that economic homogeneity, which promotes mutual trust, leads to greater rule adherence and cooperative behavior among users. But, in contrast, heterogeneity reduces the likelihood of cooperation in self-governed common-pool resource systems. The authors conclude with very useful insights for developing hybrid governance systems using a diverse set of both exogenously and endogenously crafted and enforced formal and informal rules and such governance systems can be an alternative to both market and hierarchic governance structures for managing common pool resources.

\subsection{Impacts of capacity building on local water organizations}

The institutional completeness and sophistication, though necessary, are not sufficient to guarantee performance because the latter depends ultimately on the capacity of the human medium though which institutions manifest and operate. In this sense, capacity building can be a major factor for improving institutional performance. This issue is addressed by Balasubramanya, Price, and Horbulyk in their paper: "Impact Assessments without True Baselines: Assessing the Relative Effects of Training on the Performance of Water User Associations in Southern Tajikistan". They evaluate the relative performance of two sets of water user associations (WUAs) in Tajikistan that differ in terms of the duration of training they received before their creation. Adopting a difference-in-difference method of impact assessment, the paper compares the performance of 74 WUAs created after a longer training with that of 67 WUAs created after a shorter training at two time points. Notably, the relative performance of the two sets of WUAs is evaluated in terms of four functional dimensions, i.e., irrigation delivery, system maintenance, fee collection, and dispute resolution. The difference in the performance of the two sets of WUAs between the two periods is expected to capture the impact of the length of training.

Although the paper, on the face of it, appears to be focused on an impact assessment subject, it does have an institutional economic significance in so far as the nature and level of training affect the organizational behavior and operational performance. Despite its technical problems and methodological limitations in 
isolating the impacts of training from the effects of other contributory factors, the paper is able to provide evidence for the role that training duration play in improving the organizational effectiveness and performance of local level water organizations. The results show that the WUAs that have been created after a longer duration of training had a better performance in discharging their mandated functions as compared to their counterparts with a shorter training duration during the evaluation period of 2014-2016. This result is important for designing institutional strengthening initiatives by government and donor agencies both within and beyond Tajikistan.

\section{Implications for Theory and Policy}

As the overview suggests, the papers included in this special issue evaluate different aspects of water institutions using different approaches and levels of details under diverse contexts. The evaluation context varies from macro and cross-country context to national, regional, and micro contexts. The focus of the evaluation ranges from legal, policy, and organizational aspects at the macro level to their counterparts at the micro level. The evaluation approach varies from econometric and gametheoretic approaches to analytical and historical analyses and data-based statistical and descriptive methods. Despite these variations, the papers covered in this special issue collectively provide a strong evidence for the importance of institutional aspects in improving the performance of the water sector and also indicate the changes that are needed to strengthen water institutions at different scales.

Some of the papers also demonstrate the critical linkages among institutional, economic, and political aspects of water resource management within a coevolutionary perspective but also for simmering conflicts and perverse effects caused by incoherence among or mismatch between the legal, policy, and organizational components of water institutions. The cases of Dutch Drinking Water Sector, French Water Agencies, and Pani Panchayats are instances for how these linkages can affect the performance and sustainability of water organizations in particular and water institutions in general. While the watershed study shows how incentive policies within the water context requires effective institutions, the California study shows how perverse incentives caused by subsidy policies can be eliminated through a property rights system. The Indian case study comparing physical water transfer with virtual water trade unravels not only the institutional transaction cost logic behind these technical options but also the institutional and economic significance of the resource linkages between land and water.

Besides the theoretical and policy implications of the points noted above, the papers in this special issue also open up new and broaden the existing avenues for 
future research in this important and growing area of water research. This is especially from a methodical perspective. For instance, the instrumental approach to governance indicates the feasibility and benefits of adopting an indirect way of evaluating institutional performance using easily available secondary crosssectional and time series data. Similarly, in contexts with quantitative or qualitative data constraints, depending on the scale and context, analytical and historical approaches as well as experimental methods can be used for institutional analysis and evaluation. Although institutional changes are considered to involve essentially legal, policy, and organizational reforms, they also involve a human dimension, particularly capacity building and human capital formation in the institutional realm of water resource management. 